\begin{tabular}{|l|l|l|l|l|l|}
\hline J. Tek. Ling & Vol.10 & No.3 & Hal. 265 - 270 & Jakarta, Sept 2009 & ISSN 1441-318X \\
\hline
\end{tabular}

\title{
PENGOLAHAN LIMBAH CAIR PABRIK KECAP SECARA KOAGULASI DAN FLOKULASI
}

\author{
Indriyati dan Joko Prayitno Susanto \\ Peneliti di Pusat Teknologi Lingkungan \\ Badan Pengkajian dan Penerapan Teknologi
}

\begin{abstract}
Soya bean sauce waste water is a high organic wastewater and has dark color, therefore it is difficult to degrade it biologically and also in getting clear color.

Base on as mentioned above, it is tried to process it with coagulation and flocculation use Aluminum sulfate and PAC which is added to wastewater with several doses variation of Alumunium sulfate: $(100,200,300.250) \mathrm{ppm}$ and PAC with doses (50, 100, 150, 200) ppm.

Experiment result shows that the experiment which use Aluminum sulfate and PAC as coagulant could give a good quality of processing and suitable with the threshold of wastewater. The application of floculant Aquaklir 240 could help the performance of coagulant that can be seen from the turbidity, suspended solid and flock size form.
\end{abstract}

Key words : flocculation, coagulation.

\section{PENDAHULUAN}

\subsection{Latar Belakang}

Pencemaran lingkungan merupakan masalah kita bersama yang semakin penting untuk diselesaikan karena menyangkut keselamatan, kesehatan, dan kehidupan. Salah satu permasalahan pencemaran lingkungan yang harus segera diatasi adalah masalah pencemaran air tanah dan sungai yang semakin hari semakin membahayakan bagi sumber kehidupan manusia.

Untuk menyelesaikan masalah pencemaran lingkungan ini, tentunya kita harus mengetahui sumber pencemar, bagaimana proses pencemaran itu terjadi, dan bagaimana langkah penyelesaian pencemaran lingkungan itu sendiri.

Pencemaran air tanah dan sungai terutama diakibatkan dari kegiatan domestik dan industri. Limbah cair domestik terutama berupa BOD, COD, dan zat organik sedangkan limbah cair industri menghasilkan
BOD, COD, zat organik, dan berbagai pencemar beracun.

Industri pembuatan kecap merupakan jenis industri domestik yang dalam proses pembuatannya disamping menghasilkan produk utama yaitu kecap juga menghasilkan limbah dalam bentuk cair yang berasal dari air rendaman, air rebusan, air dari proses, maupun air dari bak pencucian alat/botol; serta limbah padat yang berupa ampas kedelai.

Produk buangan dari industri kecap berupa limbah padat yang berupa ampas kedelai dan bumbu serta campuran semi kecap, sedangkan limbah cair berupa air buangan sisa pencucuian alat/mesin produksi dan air sisa rebusan kedelai.

Limbah cair pabrik kecap merupakan salah satu jenis limbah cair industri yang mempunyai kandungan bahan organik 
cukup tinggi dan kandungan warna yang cukup pekat. Bahan-bahan yang tekandung dalam limbah ini merupakan bahan-bahan polutan yang potensial menurunkan kualitas lingkungan.

Hasil pengamatan Sulistiyanti, B. Erika S. 1) limbah cair kecap mengandung COD yang cukup tinggi yaitu $31.698 \mathrm{mg} / \mathrm{l}, \mathrm{BOD}$ : $21.238 \mathrm{mg} / \mathrm{l}$, padatan tersuspensi : $3.776 \mathrm{mg} / \mathrm{l}$, fosfat : $7,47 \mathrm{mg} / \mathrm{l}$, Nitrit : tidak terdeteksi, $\mathrm{N}$ total : $78,40 \mathrm{mg} / \mathrm{l}$, minyak dan lemak : $20 \mathrm{mg} / \mathrm{l}$ dan surfaktan anion : 8,64 mg/l.

Pembuangan air limbah baik yang bersumber dari kegiatan domestik (rumah tangga) maupun industri ke badan air dapat menyebabkan pencemaran lingkungan apabila kualitas air limbah tidak memenuhi baku mutu limbah.

Berdasarkan baku mutu limbah cair yang dikeluarkan oleh Keputusan Menteri Negara Lingkungan Hidup No. KEP-51/ MENKLH/10/1995 tentang Baku Mutu Limbah Cair Bagi Kegiatan Industri ${ }^{2)}$, kandungan masing-masing polutan yang diijinkan adalah COD : $100 \mathrm{mg} / \mathrm{l}, \mathrm{BOD}$ : $50 \mathrm{mg} / \mathrm{l}$, padatan tersuspensi : $200 \mathrm{mg} / \mathrm{l}$, minyak nabati : $5 \mathrm{mg} / \mathrm{l}$, dan minyak mineral : $10 \mathrm{mg} / \mathrm{l}$.

Apabila dibandingkan antara komposisi limbah cair kecap dengan baku mutu yang diperbolehkan, tampak bahwa kandungan bahan-bahan pencemar yang terkandung dalam limbah cair kecap jauh diatas nilai ambang batas yang diijinkan. Atas dasar hal tersebut perlu dilakukan pengolahan (treatment) terhadap limbah cair agar memenuhi persyaratran untuk dibuang ke lingkungan.

\subsection{Tinjauan Pustaka}

Teknologi pengolahan limbah cair dapat diklasifikasikan ke dalam tiga metode yaitu pengolahan fisik, kimia, biologi atau atau kombinasinya. Penerapan masingmasing metoda tergantung pada kualitas air baku dan kondisi fasilitas yang tersedia ${ }^{3)}$

Salah satu metoda pengolahan limbah cair secara fisik adalah pengolahan koagulasi. Menurut Eckenfelder ${ }^{4)}$, koagulasi adalah proses kimia yang digunakan untuk menghilangkan bahan cemaran yang tersuspensi atau dalam bentuk koloid. Partikel-partikel koloid ini tidak dapat mengendap sendiri dan sulit ditangani oleh perlakuan fisik. Melalui proses koagulasi, kekokohan partikel koloid ditiadakan sehingga terbentuk flok-flok lembut yang kemudian dapat disatukan melalui proses flokulasi. Penggoyahan partikel koloid ini akan terjadi apabila elektrolit yang ditambahkan dapat diserap oleh partikel koloid sehingga muatan partikel menjadi netral. Penetralan muatan partikel oleh koagulan hanya mungkin terjadi jika muatan partikel mempunyai konsentrasi yang cukup kuat untuk mengadakan gaya tarik menarik antar partikel koloid.

Menurut Migo et al., ${ }^{5)}$, koagulasi yang efektif terjadi pada $\mathrm{pH}$ tertentu. Penggunaan koagulan logam seperti aluminium dan garam-garam besi secara umum dapat mendekolorisasi limbah cair yang mengandung melanoidin. Koagulasi merupakan proses destabilisasi muatan pada partikel tersuspensi dan koloid. Flokulasi adalah aglomerasi dari partikel yang terdestabilisasi dan koloid menjadi partikel terendapkan. Adapun bahan koagulan yang sering dipergunakan antara lain : tawas $\mathrm{Al} 2\left(\mathrm{SO}_{4}\right)^{3}$ dan Poly Aluminium Cloride, $\mathrm{AlnCl}(3 n-\mathrm{m})(\mathrm{OH}) \mathrm{m}$ (PAC).

Pembentuk flok pada proses koagulasi dipengaruhi oleh faktor fisika dan kimia seperti kondisi pengadukan, $\mathrm{pH}$, Alkalinitas, kekeruhan dan suhu air. Seperti alum apabila digunakan diluar kisaran pH optimumnya $(5,8-7,4)$, maka flok yang terbentuk akan tidak sempurna dan akan larut kembali. Namun demikian dosis bahan koagulan optimum yang ditambahkan harus ditentukan berdasarkan percobaan laboratorium dengan Jar test ${ }^{6}$ ).

Flokulan merupakan suatu bahan yang dibutuhkan untuk mendekatkan jarak antar partikel agar membentuk agregat yang cukup besar (flok) sehingga mengendap lebih cepat. Kecepatan pengendapan biasanya diperbesar dengan aluminium sulfat. 
Tawas dengan rumus kimia $\mathrm{Al} 2\left(\mathrm{SO}_{4}\right)^{3}$ (Aluminium Sulfat) merupakan bahan koagulan; yang paling banyak digunakan karena bahan ini paling ekonomis (murah), mudah didapatkan dipasaran, serta mudah penyimpanannya. Selain itu bahan ini cukup efektif untuk menurunkan kadar karbonat.

$\mathrm{Al}_{2}\left(\mathrm{SO}_{4}\right)^{3} \rightarrow 2 \mathrm{Al}^{+3}+3 \mathrm{SO}_{4}^{-2}$

Air akan mengalami : $\mathrm{H}_{2} \mathrm{O} \rightarrow \mathrm{H}^{+}+\mathrm{OH}^{-}$

Selanjutnya : $2 \mathrm{Al}^{+3}+6 \mathrm{OH}^{-} \rightarrow 2 \mathrm{Al}(\mathrm{OH})^{3}$

Selain itu akan dihasilkan asam:

$3 \mathrm{SO}_{4}^{-2}+6 \mathrm{H}^{+} \rightarrow 3 \mathrm{H}_{2} \mathrm{SO}_{4}$

Dengan demikian banyaknya dosis tawas yang ditambahkan menyebabkan $\mathrm{pH}$ makin turun, karena dihasilkan asam sulfat sehingga perlu dicari dosis tawas optimum yang harus ditambahkan. Pemakaian tawas

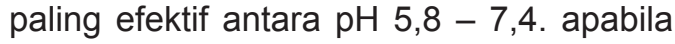
alkalinitas alami dari air tidak seimbang dengan dosis tawas perlu ditambah alkalinitas. Untuk pengaturan (menaikkan) $\mathrm{pH}$ biasanya ditambahkan larutan kapur $\mathrm{Ca}(\mathrm{OH})_{2}$ atau soda abu $\left(\mathrm{Na}_{2} \mathrm{CO}_{3}\right)^{4)}$.

Koagulan lain yang biasa digunakan adalah Poly Aluminium Chloride (PAC). Bahan ini merupakan polimer dari aluminium chlorida dan baru beberapa tahun terakhir digunakan, dikemas dalam bentuk sederhana dan siap pakai. Merupakan bahan koagulasi yang bermanfaat untuk menurunkan kekeruhan.

Biasanya untuk mendapatkan air yang lebih jernih dan mempercepat proses pengendapan ditambahkan Koagulan aid yang berfungsi membantu/memacu proses koagulasi.

Bahan yang sering dipakai sebagai coagulant aid adalah dari bahan polimer organik. Polimer organik adalah bahan organik yang berat molekulnya besar. Biasanya sering disebut juga polielektrolit.

Bahan ini ada yang asli (alamiah) dan ada yang sintetis. Polielektrolit sintetis diklasifikasikan berdasarkan atas jenis muatan pada rantai polymer sebagai berikut :

- Anion poly elektrolit : Polymer bermuatan negatif.
- Kation poly elektrolit : Polymer bermuatan positif.

- $\quad$ Polyelektrolit bukan ion : Polymer tak bermuatan.

Bermacam-macam poly elektrolit, tergantung dari pabrik yang memproduksinya seperti : Superfloc, Magnifloc, Kononfloc, Aquafloc dan lain sebagainya. Kisaran dosis anion dan kation poly elektrolit adalah 1-10 $\mathrm{mg} / \mathrm{l}$ dan nonionic poly elektrolit.

\subsection{Tujuan Penelitian}

Tujuan penelitian ini adalah melihat pengaruh dosis koagulan pada proses pengolahan limbah cair pabrik kecap secara koagulasi dan flokulasi untuk dapat memenuhi kadar limbah yang dihasilkan terhadap baku mutu limbah cair yang diijinkan.

\section{METODOLOGI}

\subsection{Percobaan Jar Test}

Jar test digunakan untuk menentukan dosis koagulan yang optimum. Alat yang dipergunakan untuk percobaan Jar test adalah floc tester yang dilengkapi dengan alat-alat gelas dan pengaduk yang sempurna, atau dapat dilakukan dengan alat pengaduk sederhana misalnya dengan pengaduk batang bamboo. Bahan koagulan yang bisa dikerjakan untuk percobaan koagulasi adalah tawas. Sedangkan untuk pengaturan kondisi $\mathrm{pH}$ biasa digunakan kapur. ${ }^{7)}$

Pada dasarnya percobaan ini meliputi:

a. Menentukan dosis bahan koagulan tawas (Alum) dan PAC yang ditambahkan variasi dosis tawas yang berbeda-beda. Alum dengan dosis 100, 150, 200, 250, 300 ppm dan PAC dengan dosis 50, 100, 150, 200 ppm.

b. Percobaan pencarian dosis koagulan dilakukan dengan penambahan flokulan tipe aquaklir PA240 sebanyak $5 \mathrm{ppm}$ untuk membantu pembuatan flok dan pengendapan. 
c. Limbah cair yang digunakan mempunyai $\mathrm{pH}$ asam sekitar 5,0 sehingga perlu ditambahkan $\mathrm{NaOH}$ agar didapatkan kondisi $\mathrm{pH}$ yang optimum.

d. Dengan kondisi pH yang telah dipilih, dilakukan optimasi berapa dosis tawas dan PAC yang tepat yang harus ditambahkan.

e. Peralatan yang digunakan antara lain : floc tester, gelas beker, gelas ukur, pipet ukur, corong gelas, turbidimeter, pH meter, kertas saring, alat pengaduk, alat pemeriksa warna.

f. Bahan yang digunakan antara lain adalah limbah cair pabrik kecap, bahan koagulan Aluminium Sulfat (tawas), PAC dan flokulan PA 240 serta digunakan pula indikator $\mathrm{pH}$ (Bromthemol blue, phenol red).

\subsection{Cara kerja}

Cara kerja yang dilakukan untuk melihat dosis koagulan dan flokulan dengan menyiapkan floc tester dan 5 buah gelas beaker. Ditambahkan bahan koagulan (tawas) dengan dosis yang berlainan 100, 150, 200, 250, 300 ppm kemudian diaduk cepat selama 3 menit, setelah itu diaduk lambat selama 5 menit dan didiamkan selama 15 menit. Diamati bentuk gumpalan, kecepatan pembentuk gumpalan, setelah itu disaring dengan kertas saring dan diperiksa $\mathrm{pH}$, kekeruhan dan warna. Kemudian dipilih pemakaian tawas optimum yang memberikan hasil terbaik, dan bilamana tidak mencapai hasil yan cukup baik diulang dengan menggunakan koagulan jenis PAC dosis 50 , 100, 150, 200 ppm. Percobaan pencarian dosis koagulan dilakukan penambahan flokulan tipe aquaklir PA 240 sebanyak 5 ppm untuk membantu pembuatan flok dan pengendapan.

\section{HASIL DAN PEMBAHASAN}

Pada percobaan ini limbah cair pabrik kecap yang digunakan mempunyai $\mathrm{pH}$ antara 5,0 - 5,2; suspended solid 357 ppm dan turbidity 107 NTU. Oleh karena
$\mathrm{pH}$ limbah cair termasuk asam, maka $\mathrm{pH}$ dinaikkan menjadi 6,5 untuk selanjutnya dilakukan penelitian dengan menggunakan Jar test dengan menggunakan dua jenis koagulan, yaitu tawas dan PAC.

Berdasarkan pengamatan yang dilakukan dengan menggunakan dua macam jenis koagulan yang dibantu dengan koagulan aid atau flokulan tipe Aquaklir PA240 dengan dosis 5 ppm diharapkan membantu kinerja dari koagulan yang dilihat berdasarkan flok yang terbentuk cukup besar.

Pengaruh dosis koagulan terhadap kekeruhan dan suspended solid pada proses pengolahan limbah kecap secara koagulasi dan flokulasi ditunjukkan pada gambar 1. Hasil penelitian menunjukkan bahwa pemberian alum dengan dosis yang semakin meningkat dapat menurunkan turbidity atau kekeruhan yang kemudian cenderung naik kembali pada dosisi yang terakhir. Sedangkan pemberian koagulan PAC dengan dosis yang semakin meningkat, nilai turbidity semakin menurun.

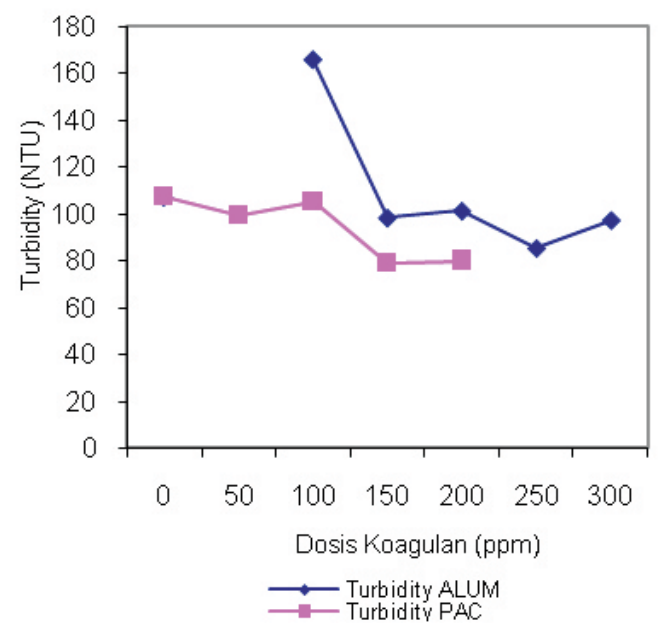

Gambar 1. Pengaruh dosis koagulan terhadap kekeruhan. 


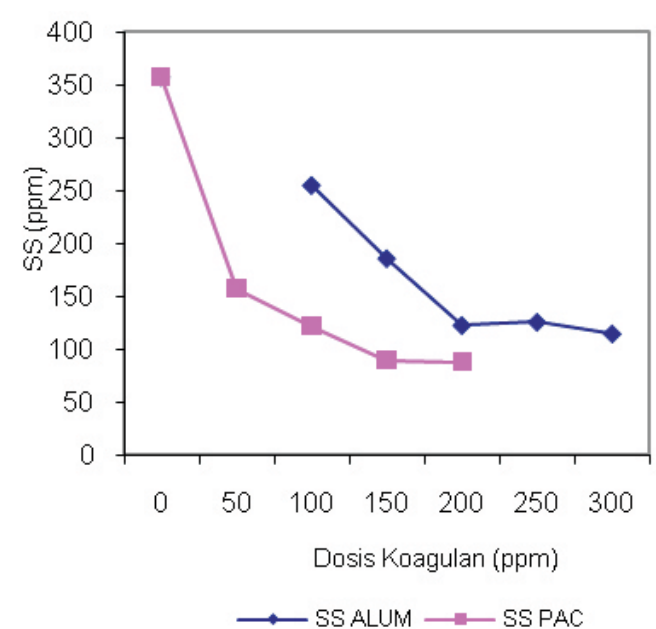

Gambar 2. Pengaruh dosis koagulan terhadap suspended solid.

Pengaruh dosis koagulan terhadap suspended solid pada proses pengolahan limbah kecap secara koagulasi dan flokulasi ditunjukkan pada gambar 2. Hasil penelitian menunjukkan bahwa jenis koagulan tawas dan PAC untuk parameter suspended solid mempunyai pengaruh sangat berbeda sekali pada proses pengolahan limbah cair kecap. Pada penggunaan tawas (Alum), penambahan dosis koagulan sampai 200 ppm meskipun dapat menurunkan secara tajam kandungan suspended solid namun penambahan ini masih belum dapat memenuhi baku mutu yang ditetapkan. Penambahan dosisi hingga 300 ppm tidak memberikan pengaruh terhadap penurunan kandungan suspended solid. Pada penggunaan PAC, penambahan dosis PAC hingga 150 ppm memperlihatkan penurunan tajam pada kandungan suspended solid hingga mencapai kandungan yang memenuhi baku mutu lingkungan, yaitu lebih kecil dari 100 ppm.

Dalam penelitian ini juga telah dipelajari pengaruh dosis koagulan terhadap ukuran flok yang terbentuk, sebagaimana dapat dilihat pada Tabel 1 berikut.
Tabel 1. Pengaruh Dosis Koagulan terhadap Ukuran Flok yang terbentuk

\begin{tabular}{|l|l|l|l|}
\hline \multirow{2}{*}{ No } & \multirow{2}{*}{ Dosis $(\mathrm{ppm})$} & \multicolumn{3}{|l|}{ Ukuran Flok $(\mathrm{cm})^{*}$} \\
\cline { 3 - 4 } & & Alum & PAC \\
\hline 1 & 50 & 2 & 3 \\
\hline 2 & 100 & 2 & 3 \\
\hline 3 & 150 & 2 & 3 \\
\hline 4 & 200 & 2 & 3 \\
\hline 5 & 250 & 2 & 3 \\
\hline 6 & 300 & 2 & 3 \\
\hline${ }^{*}$ Flokulan : PA 240 (5 ppm) \\
\hline
\end{tabular}

Dari Tabel tersebut dapat diketahui bahwa pembentukan flok pada proses pengolahan limbah cair kecap sangat tergantung pada jenis koagulan yang digunakan. Dalam penelitian ini kombinasi penambahan PA 240 sebagai flokulan dan PAC (Poly Aluminium Chloride) sebagai koagulan dapat memperbesar ukuran flok yang terjadi (diameter sekitar $3 \mathrm{~cm}$ ) dibandingkan dengan kombinasi penambahan PA 240 sebagai flokulan dan alum yang hanya dapat membentuk flok dengan ukuran diameter yang lebih kecil yaitu sekitar $2 \mathrm{~cm}$. Namun demikian dari hasil penelitian ini dapat diketakui bahwa baik pada penambahan PAC maupun alum telah dihasilkan flok yang sangat stabil.

Dari ketiga hasil penelitian ini dapat diterangkan bahwa di dalam limbah cair kecap mengandung partikel-partikel polutan dalam bentuk koloid yang terdispersi secara stabil dalam cairan limbah. Kestabilan dispersi koloid ini dikarenakan adanya penolakan elektrostratik antara muatan-muatan negarif partikel koloid tersebut. Penambahan kation yang berfungsi sebagai bahan koagulan seperti alum dan PAC dapat menetralisasi muatan koloid dan dapat menyebabkan terjadinya gaya Van der Waals sehingga partikel-partikel koloid tersebut terflokulasi menjadi partikel terendapkan. Proses flokulasi ini dipercepat dengan penambahan bahan flokulan seperti flokulan PA 240. 
Hasil penelitian ini juga menunjukkan bahwa secara umum penggunaan PAC pada proses pengolahan limbah cair pabrik kecap secara koagulasi dan flokulasi lebih efektif dibandingkan dengan penggunaan alum. Hal ini disebabkan karena PAC yang memiliki molekul lebih besar dapat membentuk flok lebih besar sehingga proses pengendapan flok lebih cepat dan efektif.

\section{KESIMPULAN}

Berdasarkan hasil penelitian terhadap proses pengolahan limbah cair kecap menggunakan bahan koagulan Alum dan PAC serta penggunaan bahan flokulan PA 240 dapat diketahui bahwa :

1. Peningkatan dosis koagulan Alum dan Poly Aluminium Chloride dapat menurunkan turbidity dan kandungan suspended solid cairan limbah kecap.

2. Penggunaan koagulan Alum belum dapat menurunkan kandungan suspended solid yang memenuhi baku mutu yang ditetapkan, sedangkan penggunaan Poly Aluminium Chloride memperlihatkan penurunan tajam kandungan suspended solid hingga mencapai kandungan yang memenuhi baku mutu lingkungan pada penambahan PAC lebih besar dari 150 ppm. Dengan demikian aplikasi koagulan Poly Aluminium Chloride dengan dosis yang tepat dapat memberikan kualitas olahan sesuai dengan standart baku mutunya.

3. Penggunaan koagulan PAC maupun Alum dapat menghasilkan flok yang sangat stabil, dengan flok yang lebih besar dihasilkan pada penambahan Koagulan Poly Aluminium Chloride

\section{DAFTAR PUSTAKA}

1. Sulistiyanti, dan Erika, B., 1994, Unjuk Kerja Bioreaktor "Fixed Bad" Dalam Penanganan Limbah Cair Pabrik Kecap, Skripsi, FMIPA, Universitas Pakuan, Bogor.

2. Anonim, 1995. Keputusan Menteri Negara Lingkungan Hidup No. KEP51/MENKLH/10/1995 tentang Baku Mutu Limbah Cair Bagi Kegiatan Industri, Kementerian Lingkungan Hidup RI, Jakarta.

3. Qasim, dan Syed, R., 1985, Wastewater Treatment Plants Planning, Design, and Operation, CBS College Publishing, New York.

4. Eckenfelder, W.W. 1986. Industrial Water Pollution. Mc Graw Hill, New York.

5. Migo, V.P., Matsumura,M., Rosario, E.J.D., dan Kataoka, H., 1993. Decolorization of Molasses Wastewate Using Inorganic Flocculant. J. Of Fermentation Bioengineering 75(6), 438-442.

6. Perry, J.H., 1963. Chemical Engineers Hand Book, $4^{\text {th }}$ ed, Mc Graw Hill, New York.

7. Anonim, 1973. Physical Chemical Wastewater Treatment Plant Design U.S. Environmental Protection Agency, Technology Transfer Seminar Publication. 